\title{
ESCRIBIR POR DETRÁS: PERMANENCIA Y DURACIÓN EN ELÁSTICO DE SOMBRA, DE JUAN CÁRDENAS
}

\author{
Simón Henao \\ Universidad Nacional de La Plata / Consejo Nacional de Investigaciones Científicas y Técnicas - CONICET \\ (Argentina) \\ simon.henao@gmail.com
}

Alba Delgado

Universidad de Buenos Aires (Argentina)

albaeledelgado@gmail.com

Recibido: 14/08/2020 - Aprobado: 28/09/2020 - Publicado: 15/04/2021

DOI: doi.org/10.17533/udea.lyl.n79a23

Resumen: Este artículo explora los vínculos entre la imaginación y la resistencia negra en el norte del Cauca. Para ello, se toma como caso Elástico de sombra, novela de Juan Cárdenas (2019), que permite indagar cómo la imaginación irrumpe en el discurso dominante para, a través de la acción de escribir «por detrás» exponer su contralado. La hipótesis principal sostiene que la narrativa del autor configura una escritura que hace inteligible a la resistencia, — esto es, le designa un lugar específico dentro del ordenamiento del lenguaje a la misma, dando a ver su permanencia en el tiempo y en el territorio.

Palabras clave: narrativa colombiana; siglo XxI; negritudes; resistencia.

\section{WRITING FROM BEHIND: PERMANENCE AND DURATION IN ELÁSTICO DE SOMBRA, BY JUAN CÁRDENAS}

\begin{abstract}
This paper explores the links between imagination and resistance of the black resistance in northern Cauca. To do this, it takes Elástico de sombra, a novel by Juan Cárdenas (2019), that allows researchers to investigate how imagination bursts into the symmetry of the hegemonic discoursein order to expose its counterpart through the action of writing «from behind». The main hypothesis points out that Cárdenas's narrative configures a writing in resistance that makes it resistance intelligible - that is, it designates a specific place within the order of language to resistance-, showing its permanence in time and its permanence in territory.
\end{abstract}

Key words: Colombian narrative; 21st century; blackness; resistance. 
«¿Por qué se respetan los derechos de Sarria si los nuestros siempre han sido pisoteados? Él entró a marcar un territorio que es nuestro, que ha sido trabajado con estas manos [...]. Somos un pueblo esclavizado que ha sido siempre pacífico. La mina es nuestra madre, y el río, nuestro padre. Somos hijos de ese matrimonio [...]. ¿A quién obedece el gobierno? ¿Acaso a nosotros, que llevamos 500 años pegados de las minas? No — dijo entre aplausos - a nosotros no nos reconoce. Por eso, señores, es que aquí se han dado las cosas que se dan.» Las palabras de la mujer fueron la más afortunada síntesis de la situación de las comunidades mineras, campesinas y pescadoras de Suárez y Buenos Aires. El oro para ellas no es un bien material en sí, es un vínculo real con su pasado, y sobre todo, con su futuro. La supervivencia de la etnia negra que trabaja las minas desde 1638 está en juego. El gobierno puede condenarlas a muerte.

Alfredo Molano. De río en río. Vistazo a los territorios negros

Nosotras resistimos porque nuestra resistencia cava un hueco en la piedra dura de la ley, para que la ley se amolde al cuerpo del pueblo.

Palabras de la maestra Fidelia en Elástico de sombra

\section{Escribir por detrás}

$\mathrm{E}$ n el noveno número de la revista América Negra — fundada en el Instituto de Genética Humana de la Universidad Javeriana de Bogotá por la reconocida antropóloga Nina Sánchez de Friedemann a comienzos de la década del noventa - aparece un inédito de 1981 de Jaime Arocha titulado «Unidades de producción nortecaucanas (Colombia): modernización y funcionamiento». El artículo de Arocha ${ }^{1}$ es un trabajo donde el también antropólogo y años después director del Grupo de Estudios Afrocolombianos de la Universidad Nacional de Colombia examina el problema de la modernización en el norte del Cauca contrastando, por un lado, las economías familiares campesinas tradicionales, donde son los mismos productores campesinos quienes controlan los medios de producción y organizan su propio trabajo (Taussig, 1993, p. 37), con el lastre burocrático que arrastran las grandes áreas de producción agroindustrial «catalogadas como típicamente modernizadas» (Arocha, 1995, p. 186), donde ya no son los campesinos quienes controlan ni la organización ni el material de trabajo. Esta diferenciación esencial entre modos de producción campesinos e industriales es también señalada, en otros términos, por Michael Taussig (1993) en su libro El diablo y el fetichismo de la mercancía en Sudamérica

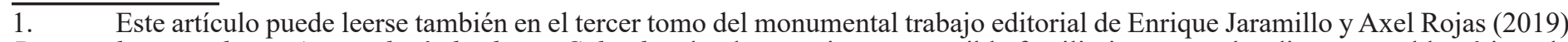
Pensar el suroccidente. Antropología hecha en Colombia donde, por cierto, es posible familiarizarse con las diversas problemáticas de la región en una amplia temporalidad que va desde tiempos prehispánicos hasta hoy. 
cuando acotó que

[e]1 modo de producción campesino difiere del modo capitalista en varios aspectos fundamentales. Bajo el capitalismo, la fuerza de trabajo proletaria carece del control sobre los medios de producción que los campesinos ejercen. El campesino usa dinero, no capital, y vende para poder comprar, mientras que el capitalista usa el dinero como capital para comprar y poder vender ganando, sumando así el capital y repitiendo el circuito a una escala siempre creciente, para que la empresa no muera. El productor campesino vive en un sistema que apunta a la satisfacción de un conjunto de necesidades cualitativamente definidas; por el contrario, el capitalista y el sistema capitalista tienen como objetivo la acumulación ilimitada de capital (p. 45).

A todo esto, la importancia de la labor etnográfica de Nina S. de Friedemann, quien introdujo la noción de «huellas de africanía», radica en haber documentado, como apuntó Arocha (2016) en un artículo conmemorativo,

el origen y transformación de las culturas que porta la gente negra [lo cual] implicó seguirles el rastro a esas memorias africanas, reinterpretadas en América y muchas veces escondidas para defenderlas de la persecución inquisitorial, pero que - como sucedió con los toques de tambor y lo demostró Friedemann - fueron fundamentales para ejercer la resistencia contra el cautiverio. Además, ella deletreó la paradoja que involucró este ejercicio de recordar escondiendo para resistir ${ }^{2}$, pero al mismo tiempo - en especial a partir del período republicanopugnando por la inclusión ciudadana (p. 137).

La revista América Negra está enmarcada dentro del surgimiento de los debates académicos y políticos acerca de la cuestión étnica y racial vinculada a la población negra en Colombia; un aspecto de la composición social, política y cultural del país que, a pesar de las denuncias de los pioneros de los estudios afrocolombianos y de los mismos Friedemann y Arocha, había sido invisibilizado hasta entonces, en contraste con la focalización en las poblaciones indígenas, como señalaron Barbary y Urrea (2003, p. 50). En este marco, resulta ilustrativo observar cómo durante las últimas décadas del siglo xx empieza a existir un anudamiento, no sin tensiones, entre las políticas de la identidad negra y la literatura académica (Restrepo, 2003, p. 243). Arocha (1995) describió la zona plana del norte del Cauca como una zona donde sobreviven veredas en las que se cultivan cacao, café y otros productos alimenticios. «Los pequeños agricultores de estos enclaves», escribió Arocha (1995, p. 185), «funcionan dentro de una economía tradicional que se mantiene activa gracias al trabajo familiar» (p. 185).

Pero ya en la época de América Negra, Arocha, junto con otros investigadores de la región como el mencionado Michael Taussig, advertían que los días del campesinado nortecaucano estaban contados, «pues la tierra en que fundamenta su existencia irá pasando a los ingenios azucareros a medida que disminuya su oferta» (Arocha, 1995, p. 185). A pesar de ello, Arocha señaló la particularidad de la cultura campesina y minera negra — que él llama afroamericana - del norte del Cauca que, junto con la viabilidad ecológica del modelo tradicional campesino, les da a los enclaves cierta autonomía y dinamismo propios, «y por lo tanto una proyección amplia hacia el futuro» (p. 185). La amplitud de esa proyección hacia el futuro previsto por Arocha en las últimas décadas del siglo xx - y viendo ahora que han avanzado las dos primeras del xxI - bien podría sintetizarse, para inscribir la experiencia de esta situación en un todo significativo, como la temporalidad permanente de la resistencia. Dicho de otro modo, como un cúmulo de estrategias del presente que existen para que, incluido el pasado que la constituye, la resistencia permanezca en el territorio, allí donde permanecer significa la presencia ancestral de

2. Cursivas propias. 
Escribir por detrás: Permanencia y duración en Elástico de sombra, de Juan Cárdenas

los cuerpos instituidos como sujetos políticos en el territorio que continua y colectivamente se enfrentan a las diversas violencias con que les ha sido negada, por una larga duración, la pertenencia.

En ese sentido, resulta significativo observar que el suroccidente colombiano, y particularmente el departamento del Cauca, ha sido, desde épocas coloniales, un escenario de diversas experiencias de resistencia, no solamente negras, sino tambiénindígenas. Esto lo ha estudiado con amplitud, por mencionar un trabajo entre muchos, Joanne Rappaport (2000) en La política de la memoria: interpretación indígena de la historia en los Andes colombianos a propósito del pueblo nasa — el pueblo que «nunca ha sido vencido» (Hernández, 2006, p. 191)— donde se expone la idea tanto de una resistencia que funciona en virtud de la memoria, como de una memoria que se construye en función de la resistencia (p. 30). Acerca de esta característica de las poblaciones negras e indígenas en el Cauca entre los que ha habido alianzas y rivalidades a lo largo de los siglos (Mina, 1975, p. 33)—, Esperanza Hernández (2006), quien investigó sobre la resistencia pacífica de los cabildos caucanos y su relación con el ejercicio de la autonomía, señaló que

[e]ste departamento se ha caracterizado por la resistente huella de la historia en la generación de profundas desigualdades, diversas formas de exclusión e injusticia social; la composición multiétnica y pluricultural de su población, expresiones de acumulación de riqueza y de pobreza extrema; presencia de diversas modalidades de violencia; y la emergencia y consolidación de movimientos sociales, iniciativas de paz desde la base y experiencias de resistencia civil (p. 182).

A lo largo de este artículo se busca explorar las formas con que la imaginación se encuentra involucrada con la temporalidad de la resistencia. Cuánto de ella, de la imaginación, concierne a la permanente temporalidad con que la resistencia, y específicamente la resistencia negra en el norte del Cauca, se expone y se practica como una forma necesaria de la acción comunitaria. Para indagar sobre esta relación entre imaginación y resistencia se parte del hecho de que la imaginación, comúnmente entendida, no solo constituye un nexo entre la ficción y lo real, entre el relato y la urgencia, sino que también, y quizás más aún, es aquello que indica, señala y hace visible la permanencia en el tiempo de lo que no es — o no ha sido aún — parte del relato dominante; de lo que ha sido alojado, por decirlo vulgarmente, en el «cuarto trasero de la historia» o, para usar el término derridiano evocado por Gabriel Giorgi (2020) al hablar de la narrativa de Juan Cárdenas, aquello que ha sido tachado del archivo (s. p.).

Como formadora de visibilidad, la imaginación irrumpe en el discurso dominante de la narrativa institucional y de la historia oficial para exponer su contralado a través de la acción de escribir por detrás, como diría Bruno Mazzoldi (2020) con su lucidez poética. Hay novelas y relatos, como La vorágine, de José Eustasio Rivera, como La casa grande, de Álvaro Cepeda Samudio, como Changó, el gran putas, de Manuel Zapata Olivella, como La ceiba de la memoria, de Roberto Burgos Cantor o como Elástico de sombra, de Juan Cárdenas que, en términos generales, hacen inteligible a la resistencia, esto es, le designan un lugar específico dentro del ordenamiento del lenguaje, dando a ver su permanencia en el tiempo, exponiendo a los lectores su duración; a pesar de sus marcadas diferencias en tanto aparatos de construcción, circulación y proyección de imaginarios, usando el relato, los dobleces del lenguaje y su potencial imaginario. 


\section{Permanencia alterada}

En una columna de opinión publicada el 22 de junio del 2020 en el diario El País de España a propósito de la falsa pureza blanca española con la que tantos ibéricos se identifican y en el contexto de los reclamos antirracistas que en medio de la pandemia por el coronavirus se han hecho oír en las principales ciudades del mundo tras el asesinato de George Floyd por la policía de Michigan, el escritor colombiano Juan Cárdenas afirmó que, para abandonar el paternalismo blanco con que se asumen las reivindicaciones de lo negro, es urgente reflexionar sobre la «blanquitud», es decir, sobre lo blanco

entendido como una construcción histórica, económica y política, $[\ldots]$ lo «blanco» como una ideología que se ha implantado gradualmente hasta el punto de que se lo asume como una realidad cromática o hasta biológica, como una distinción natural que separa a unos cuerpos de otros (y ya sabemos que eso es precisamente lo que hacen las ideologías, naturalizar las arbitrariedades, modificar incluso las percepciones) (2020, s.p.).

En ese mismo sentido, en palabras de Bolívar Echeverría (2011), la blanquitud hace parte del reconocimiento del racismo constitutivo de la modernidad capitalista, ya que esta «exige la presencia de una blanquitud de orden ético o civilizatorio como condición de la humanidad moderna» (p. 146). Esta condición es la que ha intentado desacoplar Juan Cárdenas, exponiéndola en su novela Elástico de sombra, publicada en el 2019: la de una blanquitud comprendida como construcción implantada y como maquinaria de la ideología colonial productora y propagadora de racismos y de otras violencias que acompañan los procesos de identidad nacional, aun cuando en el discurso de las formaciones nacionales americanas haya sido propagada — a conveniencia — la idea criolla de una igualdad racial como característica de la americanidad. Este asunto ha sido bien estudiado, a propósito del caso colombiano, por Alfonso Múnera en El fracaso de la nación (1998) y Marixa Lasso en El mito republicano de la armonía racial (2013); y también ha sido explorado e interpelado por el videoartista José Alejandro Restrepo en su obra de 1998 Teoría del color (una contribución al desorden en las taxonomías) para dar cuenta del racismo y la discriminación presentes en los discursos de toda una saga de déspotas ilustrados, próceres y prohombres de la intelectualidad colombiana, como Pedro Fermín de Vargas, José María Samper, Luis López de Mesa, Laureano Gómez o Francisco José de Caldas, de quien se dice en Elástico de sombra que es «un dizque sabio que decía que los negros eran brutos, arrechos y perezosos» (2019, p. 89). En definitiva, se trata de una blanquitud que es parte constitutiva de los procesos identitarios nacionales y que, como precisó Echeverría (2011),

por más que se conforme en fundación de empresas estatales asentadas sobre sociedades no europeas (o sólo vagamente europeas) por su «color» o su «cultura», es una identidad que no puede dejar de incluir, como rasgo esencial y distintivo suyo, un rasgo muy especial al que podemos llamar blanquitud. La nacionalidad moderna, cualquiera que sea, incluso la de estados de población no-blanca, requiere la blanquitud de sus miembros (p. 147).

La novela de Juan Cárdenas — que en la edición de Sexto Piso lleva el Candombe de carnaval de Pedro Figari reproducido en su tapa, un óleo nativista de 1932 que se encuentra en el Museo de Bellas Artes de Buenos Aires - propone el desacoplamiento de la blanquitud a través de un relato cuyas derivas oscilantes entre el realismo y lo fantástico son capaces de incluir su propia sintomatología. Se trata de una novela que, entrando en 
un divertimento taxonómico, puede catalogarse como de «realismo elástico», ya que construye un dispositivo narrativo en permanente movimiento. Si como señala Mark Fisher (2018) «lo Real es lo que continúa repitiéndose, lo que se reafirma a sí mismo sin importar cómo intentemos huir de él» (p. 250), el realismo elástico es una estrategia narrativa que irrumpe para torcer la continua repetición de lo Real, que indaga - entre las formas y las sombras del archivo - por los posibles vericuetos gracias a los cuales se hace posible la huida, la torcedura, la resistencia. Al igual que los cuerpos candomberos que se mueven al ritmo de los tambores del óleo de Figari; al igual que los cuerpos practicantes del legendario arte de la esgrima del machete, «...también conocida como "grima”, un arte marcial negro de origen incierto actualmente en una fase vestigial o de ruina» (Cárdenas, 2019, p. 7); al igual que los machetes de ese arte marcial que se practica en las montañas del Cauca, que fue usado por los ejércitos de negros durante la Guerra de los Mil Días y la Guerra con el Perú, que le sirve de escenario y motivo al relato, y cuya historia vinculada al territorio caucano y a los negros patianos Cárdenas sintetiza en el epílogo; en fin, al igual que cuerpos y machetes, Elástico de sombra traza un movimiento permanente que ondula evocando una especie de ritualización y de performatividad con la que cobra cuerpo la permanencia alterada, esto es, una particular forma de la temporalidad que supone una presencia de los cuerpos cuyo aliento, sostenido en el tiempo, asume la alteración, el desvío, la torcedura y el desalineo como posibilidades de repensar las condiciones de lo existente.

Esta performatividad es un acto crítico que busca el desacoplamiento de la blanquitud a través de la construcción de imágenes que llegan a hacerse acaso elásticas, como los trazos que marca al final de la novela uno de los maestros macheteros cuando le dice a otro que

[...] nuestras líneas rectas no son rectas. Pero no porque no sepamos o no podamos imaginarnos una línea recta. Nuestras líneas no son rectas porque en la vida real todo gesto, todo trazo, por fino y exacto y perfecto que sea, siempre deja a los costados una rebaba (2019, p. 110).

No es una permanencia estática entonces, sino una permanencia alterada, análoga a aquello a lo que alude Mayka García-Hípola (2011) cuando, a propósito de la obra del célebre arquitecto Peter Eisenman, habla del paso del trabajo con objetos al trabajo con las huellas - en este caso, en el vocabulario de Friedemann, huellas de africanía - que dejan los procesos. El ardid que hace posible la alteración como forma de lo existente, dice la autora ), «es el paso del signo al texto, de la sintaxis a la semántica y de la gramática a la memoria» (p. 17). Y más adelante complementa: «Al utilizar elementos que son fragmentos artificiales transhistóricos como herramientas de proyecto, el acto crítico consiste en una descomposición de fragmentos una vez que han superado su historia gracias a su remontaje» (p. 18).

Como en las novelas de Aira o en las películas de Adirley Queirós, donde conviven tradiciones y elementos diversos entre la fantasía y lo cotidiano, la ficción y lo documental, los pedazos de la historia brasileña o argentina y la mitología extraterrestre de naves alienígenas o viajes en el tiempo (Zgaib, 2020, p. 35), el dinamismo narrativo característico de la obra de Cárdenas responde al movimiento propagado por la constante alteración del relato. Este es un dinamismo que bien puede ponerse en contraposición a una tradición narrativa como la colombiana, 
Escribir por detrás: Permanencia y duración en Elástico de sombra, de Juan Cárdenas

que, salvo pocas excepciones, se caracteriza por una estática monumental.

En Elástico de sombra, la novela con la que Cárdenas aborda las resistencias de las poblaciones negras del norte del Cauca en el suroccidente colombiano, donde se personifica al viento como un ser animado, y donde hay pactos con entidades maléficas como las brujas; donde hay chivas con latonerías ornamentada

en las que se miraba un jurgo de bestias salvajes, peludas y no tanto, caribajitos y carisecas, vivos y cocinados, canastos con frutas, pajaritos, paisajes de las montañas, paisajes del valle, paisajes del mar, cielos de todos los tonos y hasta ciudades futurísticas con platillos voladores $(2019$, p. 15).

En esta novela, donde hay aventuras en cruces de caminos y transformaciones en bestias con alas que sobrevuelan todo el valle; donde hay diálogos con el señor Duende para pedirle los conocimientos perdidos de los macheteros y al término de la cual se interna en su guarida subacuática; donde hay logias de mujeres macheteras; donde hay peleas entre duendes y diablos y donde hay diablos encarnados en videoartistas de vanguardia; allí, en esta obra, la permanencia alterada aparece con mucha elocuencia como resultado de múltiples, y en ocasiones contradictorias, conjugaciones de todos estos elementos que, al igual que los fragmentos artificiales transhistóricos que menciona García-Hípola, articulan tradiciones, lenguajes, realidades e imaginarios, impidiendo que se instaure como un aparato monumental y estático. En ese sentido, Elástico de sombra no es un relato fijado sino, más bien, un artefacto narrativo de la contra-información como forma de la resistencia y un tejido textual complejo cuyos procedimientos, como los cuerpos sudorosos que practican la esgrima de machete o bailan el candombe $-\mathrm{y}$ también como las montañas que sus personajes recorren y en cuyos pliegues «las cosas aparecían y desaparecían de manera caprichosa» ( p. 55) — se mueven constante y sorpresivamente hacia múltiples direcciones, siempre en contra de aquello que es dominante, dejando en cada uno de sus momentos las marcas de tales desplazamientos.

Si la narrativa de Cárdenas se caracteriza por producir una búsqueda de la forma mediante la superposición de capas (Henao \& Delgado, 2020) no es de extrañar que el dinamismo narrativo de Elástico de sombra no impida, de ninguna manera, que a él se le superponga un enfático posicionamiento de la escritura frente a una situación histórica y política específica que la connota pero que, a la vez, la trasciende: la de la resistencia negra en el norte del Cauca. Se trata de una resistencia transhistórica - una huella de africanía - en la que puede trazarse un vínculo con las acciones pasivas o activas que se realizaron al interior de los barcos traficantes de esclavos desde África hacia América $^{3}$ (Zuluaga, 2010, p. 94), y que, ya en tierra americana, llevaron a ejercer la territorialidad como forma de construcción de comunidad «que les brindara [a los palenques] posibilidades de establecer relaciones de sociabilización, organización del parentesco, y participar de la construcción de una cierta sociedad civil» (, p. 96). Desde mediados del siglo XIX y tras la abolición de la esclavitud, esta resistencia en el norte del Cauca ha estado organizada en defensa del territorio y la cultura negra. Michael Taussig, quien ha estudiado ampliamente las características sociales del suroccidente colombiano a través de las tensiones entre las fuerzas políticas y las relaciones sociales que forjan el aparato funcional de los modos de producción, ha identificado distintos momentos de resistencia campesina negra en el Cauca desde la abolición de la esclavitud en 1851.

3. Así también lo ha poetizado el escritor Manuel Zapata Olivella en su novela totalizante Changó, el gran putas, en relación con territorios más amplios y con estrategias narrativas quizás antagónicas a las de Juan Cárdenas. 
Escribir por detrás: Permanencia y duración en Elástico de sombra, de Juan Cárdenas

Según el autor, uno de esos momentos se dio cuando el campesinado negro del norte del Cauca, los exesclavos y sus descendientes, desarrollaron una economía de subsistencia «estableciéndose ilegalmente en las tierras de sus antiguos amos» (Taussig, 1993, p. 80), lo que conllevó a duras luchas armadas entre campesinos y sectores políticos que representaban a los antiguos amos — como los aún hoy homenajeados esclavistas de la familia Arboleda, por ejemplo - y a los grandes terratenientes. Taussig (1993) enfatizó en que este campesinado negro fue perseguido durante toda la segunda mitad del siglo xIX y no tuvo representación política alguna:

carentes de seguridad en cuanto a la tenencia de la tierra, y sin la posibilidad de contar con una estructura representativa de pueblo dentro del marco oficial de la administración, los campesinos negros formaron una nueva clase social que quedó fuera de la sociedad [...]. Violentamente excluidos de la sociedad, los campesinos se vieron forzados a desafiar sus instituciones y sus ideas (p. 87).

Otro fue el momento que emergió con el fin de la Guerra de los Mil Días en los primeros años del siglo xx, cuando la centralización política de la república protegió a los grandes terratenientes y apareció una gran afluencia de capital estadounidense que, mediante la construcción del ferrocarril que unió el Valle del Cauca con el Pacífico, favoreció la industrialización de la tierra con fines de cubrir el mercado internacional (Taussig, 1993, p. 101). En ese momento, con empresarios como Santiago Eder, cónsul de los Estados Unidos y amigo íntimo del presidente Rafael Reyes, la industria azucarera y sus grandes cultivos de caña de azúcar trastocaron la naturaleza campesina de la región, imponiendo una precaria proletarización como forma de vida asalariada. La tenencia de la tierra pasó a ser, casi en su totalidad, de los grandes terratenientes, ya no hacendados, como en el siglo XIX, sino industriales en búsqueda de progreso, para quienes las prácticas de subsistencia campesina representaban un obstáculo y una amenaza. Este proceso se intensificó con La Violencia de mediados del siglo xx, que aceleró la transferencia de tierras campesinas a los grandes acumuladores de tierra y capital de la industria azucarera (Taussig, 1979, p. 12).

A estos momentos identificados por Taussig se hace necesario agregar otra condición de la resistencia negra en el Cauca, vinculada en este caso, a la minería, actividad también determinante para comprender la permanencia alterada como una forma de temporalidad, con la cual se configura el relato en la novela de Cárdenas y que, inscrita como acto crítico, asume la alteración, el desvío, la torcedura y el desalineo como posibilidades de repensar las condiciones de lo existente. La minería, que en muchas zonas del suroccidente colombiano ha sido durante siglos el fundamento económico de las poblaciones — «...la mina es nuestra madre, y el río nuestro padre. Somos hijos de ese matrimonio...» (Molano, 2017, p. 108)—, les ha dado, paradójicamente, autonomía a los pueblos negros; pero, a la vez, y desde las últimas décadas del siglo xx, ha puesto en riesgo su existencia ${ }^{4}$. Esto es a lo que apunta la activista Francia Márquez, «uno de los rostros más visibles de la lucha social y comunitaria en contra de ese modelo» (Zuluaga, 2018, s.p.), cuando aparece como personaje en Elástico de sombra y arenga a una multitud congregada en los preparativos para ir a la minga:

4. Véase La Toma: historias de territorio, resistencia y autonomía en la Cuenca del Alto Cauca (Ararat et al., 2013, p. 179) y «Las mineras de La Toma. Resistencia negra en defensa de la vida y el territorio» (Bolívar \& Ibarra, 2017, p. 161). 
Sabemos cuál es la historia y no nos van a venir a engañar con cuentos, sabemos quiénes somos, quiénes fueron nuestros opresores y cómo obtuvimos el derecho a vivir aquí: fue con trabajo, compañeros y compañeras. No somos los propietarios, somos los cuidadores, los guardianes de estas tierras. Los que sabemos cuidar de la vida. Y por eso nos atacan, por eso nos persiguen, por eso nos desplazan y por eso nos matan. Porque ellos, este Gobierno, donde encontraron guarida los descendientes de quienes esclavizaron a nuestros tatarabuelos hace cuatro siglos, hoy son agentes al servicio de una gran máquina global de la muerte, que subsiste gracias a la producción de muerte. Y nosotros somos todo lo contrario: nosotros producimos y cuidamos la vida. [...] Defender cada palmo de nuestro territorio es defender la vida. Ellos quieren tierra para destruirla con su ganado y sus monocultivos y su minería depredadora. Nosotros no queremos tierra, queremos territorio (Cárdenas, 2019, p. 65).

En palabras de Alfredo Molano (2017), la mina es «la gran teta» (p. 103) de la que estas poblaciones han vivido desde la abolición de la esclavitud y la explotación a pequeña escala «es la garantía de supervivencia de su gente, de su raza, de su cultura. Por esa razón están dispuestos a dar su vida» (p .103). La práctica ancestral de la minería artesanal en este marco ha funcionado también como herramienta de lucha y de resistencia en defensa del territorio heredado que, como dicen Bolívar e Ibarra (2017) a propósito de las mineras de La Toma, «le permite a la comunidad permanecer en el tiempo, conservando su identidad, tradición y forma de organización social» (p. 163).

La agricultura campesina y la minería artesanal pueden entenderse como herramientas de resistencia negra en el Cauca, en tanto son prácticas ancestrales que responden colectivamente a los distintos modos de violencia con que la modernidad, unida a la conquista y el tráfico de esclavos, pretende conquistar el territorio, desde el siglo XIX hasta hoy. Elástico de sombra — y en ella el arte de la esgrima de machetes que le sirve de motivo-, es también factible de ser entendida como una extensión de la práctica de la resistencia, como una de sus múltiples y diversas acciones en un territorio donde «la guerra no se acaba nunca [...] la guerra sigue y sigue y sigue» (Cárdenas, 2019, p. 53). Esta factibilidad de lo literario como acción de resistencia, sin embargo y como es de suponer, conlleva un sinfín de interrogantes acerca de cómo interviene la literatura en tanto arte performática y con ella la imaginación en la organización de acciones de resistencia: cómo se convierte una novela — de realismo elástico-, y las imágenes narradas que la componen, en acción de resistencia, y cómo el lenguaje, en su expresión literaria, se vuelve fuerza material en la construcción de acciones de resistencia, de la no aceptación de lo dado (Zemelman, 2011, p. 81).

\section{Intensidad de la duración}

Todos estos interrogantes están inmersos en una cuestión bastante más amplia que Ángel Rama trabajó profusamente en La ciudad letrada hacia finales de la década de los setenta y - como acotó Beatriz Colombi (2006) — en su artículo «La señal de Jonás sobre el pueblo mexicano» (1982), donde aparecen las voces populares, esas «plurales lenguas americanas», que proliferan en la literatura colonial novohispana del siglo XVII y que, al decir de Rama, dieron pie a la conformación de una nacionalidad plebeya en la colonia. Pensar la escritura de Cárdenas como una escritura por detrás, como un arte de la contra-información (Deleuze, 2008, p. 288) y como 
Escribir por detrás: Permanencia y duración en Elástico de sombra, de Juan Cárdenas

un acto de resistencia implica, en todo caso, reconocer que se trata de un recurso de la imaginación que tiene marcadas limitaciones en el agenciamiento popular, aun cuando, según Rama, la literatura sea un espacio propicio y, de alguna manera, privilegiado para que las voces populares se organicen materialmente. Pero esa disposición de la literatura, y particularmente de la novela, hacia lo popular ya ha sido puesto en cuestión por las derivas teóricas de la subalternidad desde fines de la década de los noventa del siglo pasado. Se tiene, por ejemplo, al reflexivo John Beverly de Subalternidad y representación (2004) con aquellos intentos — que él mismo reconoce como fallidos - de establecer los límites con que la literatura representa a los sujetos subalternos (p. 30), así como con sus agudas críticas a la noción de transculturación propuesta por Ángel Rama como instrumento para alcanzar la modernidad cultural y económica de América Latina (p. 77).

Aun con estas limitaciones a cuestas, una posible respuesta a los interrogantes acerca de la factibilidad de lo literario en tanto acción de resistencia en una narrativa dinámica como la de Juan Cárdenas, es la existencia de una profunda búsqueda de estrategias narrativas que apuntan hacia una «desjerarquización» cultural y, con ello, hacia una redefinición del orden social que no proviene exclusivamente de la cultura letrada sino, más bien, de los sectores populares. Por ello, Elástico de sombra puede ser leída como una performatividad discursiva que se encuentra situada en un entre-lugar que abarca tanto la ciudad letrada, desde su origen y su destino, pero que contiene en sí una deslocalización de la ciudad letrada y una relocalización que, en su carácter performativo, participa del discurso territorial de la resistencia ancestral.

Esto es algo que puede verse en al menos dos niveles que suponen distintas intensidades de la duración, ya que, al tratarse de una narración que está sujeta a una forma de la experiencia sensible que no prescinde de la voluntad del relato, sino que, por el contrario, lo multiplica, abandona la forma lineal del tiempo y, con ello, la altera y habilita la permanencia de diversos pasados proyectados en el presente móvil de la enunciación. Si bien la novela simula una deriva, aparecen en ella las multiplicidades, contradicciones y heterogeneidades de los tiempos — cualidades propias de la duración según Braudel (1969, p. 62)_, por lo que no puede decirse que Elástico de sombra sea un relato en línea recta: en esta obra hay acciones, en efecto, pero no necesariamente movimientos. Esto es lo que hace que el espacio representado en Elástico de sombra, ese espacio de montañas andinas que recorren los personajes, sea un espacio lleno de las intensidades de los tiempos superpuestos.

Esto quiere decir que los dos niveles o gradaciones de la intensidad de la duración en las que se detiene este trabajo concuerdan con el deseo del relato de no diluir la historia ni el carácter histórico de los hechos sociales, ni mucho menos los hechos discursivos, y con la estrategia de socavar enfáticamente el procedimiento por medio del cual el lenguaje constata las condiciones de posibilidad con que un sistema lingüístico — en este caso el relato o la narración fabulosa de los hechos - aparece como partícipe de la dimensión histórica en la que se producen los hechos sociales.

Con la lógica dinámica del relato que caracteriza a Elástico de sombra el tiempo no se abstrae de la trama, sino que está plenamente comprometido con ella, de manera que se produce una equivalencia entre la trama y el tiempo. Cuando don Floro, uno de los líderes indígenas que aparece en la novela, «pedagógico como suele ser el 
Escribir por detrás: Permanencia y duración en Elástico de sombra, de Juan Cárdenas

pueblo nasa» (Cárdenas, 2019, p. 82), dice que «en estas montañas estamos peleando dos guerras: la del siglo XIX y la del siglo XXI» (p. 82) no está simplemente poniendo en escena el coeficiente histórico de la violencia colonial de la modernidad en su carácter acumulativo, sino que está poniendo en discurso la equivalencia entre tiempo y trama de la historia, esto es, haciendo inteligible la temporalidad de la resistencia. Esta es una equivalencia que se puede identificar como duración: allí el tiempo y la historia son reductibles y, por lo tanto, el estado precedente no es separable del estado posterior de los hechos relatados. Lo que hace posible que exista esa lógica dinámica del relato en gradaciones de intensidad de la duración - esa particular forma del tiempo donde los tiempos son coextensivos - es un ordenamiento de los signos tal que la hace inteligible constituyéndola en imágenes y convirtiéndola en una sustancia animada.

Uno de estos niveles o gradaciones que hacen inteligible la intensidad de la duración en Elástico de sombra se encuentra en la relación entre la escritura y la oralidad. Esta gradación está implícita en el hecho de que en la novela de Cárdenas no se presenta una escritura que se encuentre interrumpida por otras formas de la narrativa como la oral, si bien hay un desdoblamiento del lenguaje y una escritura que se abre hacia la tradición oral del relato. No cabe duda de que se trata de un artefacto plenamente escriturario o de una práctica textual hegemónica vinculada a la producción y circulación de textos escritos, para decirlo en palabras cercanas a Martin Lienhard, estudioso del tema y autor de La voz y su huella (2003) para quien «la incorporación del discurso oral por parte de los letrados oficiales, muy frecuentemente en América Latina a lo largo de la historia colonial y poscolonial, obedece siempre al propósito de producir un discurso de cierta representatividad social» (Del Llano, 1995, p. 296).

Pero es esta misma razón la que permite afirmar que no existe una verdadera diferencia entre el registro de la escritura y el registro de la oralidad a lo largo de Elástico de sombra. Al no haber una interrupción de lo oral que se interponga en lo escritural - a la manera del costumbrismo colombiano de Tomás Carrasquilla o a la necesidad de un glosario en La vorágine, por ejemplo - no existe una diferencia entre un registro y otro, como tampoco hay una mezcla, una hibridación o una síntesis, algo que, por cierto, sí está presente de manera bastante significativa en Los estratos, la novela que Cárdenas publicó en 2013. Elástico de sombra es distinta. Lo que hay en ella es una polifonía «sin fusión homogénea» (Antelo, 2019, p. 114) donde conviven en tensión las materialidades discursivas provenientes del archivo heterogéneo de la ciudad letrada con, entre otras, las jergas macheteras — «torno, defensa, avance, carrielero, transversal bajo, falso y estocada» (Cárdenas, 2019, p. 100)—, campesinas, mineras, negras e indígenas de la región del Cauca colombiano y demás huellas escritas de las voces marginadas, como lo diría Lienhard (2003, p. 15). Es una apertura donde las dicotomías de lo escrito y lo oral, de lo letrado y lo popular, se encuentran intervenidas performativamente, sin predominio de lo uno sobre lo otro ${ }^{5}$, en virtud de una estrategia narrativa de dinamismo que habilita el propio artefacto literario.

El otro nivel o gradación con la que se hace inteligible la intensidad de la duración y que permite afirmar que en Elástico de sombra hay una redefinición del orden social y cultural es, quizás, un poco más minucioso, y

5. Este es un punto clave en la crítica que Beverly (2004) hace sobre la idea de transculturación en Rama (p. 77) y que, en parte, comparte Martin Lienhard (2003, p. 171). 
Escribir por detrás: Permanencia y duración en Elástico de sombra, de Juan Cárdenas

está vinculado a una estrategia narrativa del orden de los personajes y sus derivas. Esto toca específicamente a la personificación de Cero, el «escribidor blanquito, así medio cafeconleche, que vivía con el hocico metido en cosas de negros» (Cárdenas, 2019, p. 11) que a lo largo de la novela acompaña a don Sando y a Miguel, maestro y contramaestro macheteros, en sus aventuras por todo ese «valle endemoniado» (p. 12), por las montañas de la Cordillera Occidental y la región del Patía por donde van en búsqueda del «paradero del conocimiento perdido» y de «recuperar las paradas de esgrima de machete desaparecidas» (p. 29), particularmente de la técnica de juegos de sombra y, dentro de ella, de

el famoso Elástico de Sombra, juego tal vez apócrifo, tal vez un simple cuento para distraer quicatos, pero no por eso menos legendario. Un juego, según se contaba, muy antiguo, unos decían que de origen africano y otros que dizque traído de Haití durante las campañas libertadoras de Bolívar; en todo caso, un juego que requería de una malicia de orden superior, pues consistía en saber atacar y defenderse en la más absoluta oscuridad. Quien dominara el Elástico de Sombra sería capaz de luchar hasta con los ojos vendados, guiándose nada más que por una intuición especial que la técnica permitía cultivar y desarrollar. El máximo adagio machetero de Ojo y más Ojo, Visual y más Visual, quedaba de este modo trastocado por una nueva luz. O por una nueva sombra, para ser más precisos (p. 40).

En términos generales, los personajes de las novelas y cuentos de Cárdenas, como Cero, Miguel y don Sando, son figuras que se benefician de las formas en que están expuestas, personajes que se funden en la materialidad discursiva que los compone. Al decir fundirse, se quiere decir que se quedan y permanecen, que habitan durante un cierto tiempo en esa materialidad discursiva. Es lo que sucede con las mujeres con quienes se experimenta y se hacen pruebas de una nueva droga en Ornamento, o también con el jíbaro amigo del protagonista de El diablo en las provincias, que gusta de bañarse a oscuras. Y en ese asentarse en la fisicidad de las palabras, los personajes de las novelas de Cárdenas se constituyen como sujetos políticos, aparecen con tensiones particulares que surgen del y con el lenguaje, de su ordenamiento y de todo el entramado discursivo que compone el espacio textual del relato, pero que se sitúan en una posición alterada, singular, provisoria, local y territorializada. Es esa territorialidad en todo caso cambiante, muchas veces deslocalizada y que está permanentemente abierta a la posibilidad de una agencia ya no individual, sino colectiva, lo que hace que las figuras de Cárdenas sean personajes que se plantean, insistentemente, como sujetos políticos atravesados por el lenguaje, por la articulación y el encadenamiento de las palabras.

Esto significa que se trata de sujetos políticos que no aparecen como una representación figurativa de lo real, aun cuando muchas de las estrategias de ciertos realismos son replicadas en su escritura ${ }^{6}$. Al no aparecer como una representación figurativa de lo real, las figuras de Cárdenas, constituidas como sujetos políticos, aparecen en función de todo un entramado textual. Muchas veces los encadenamientos que tejen ese entramado son paradójicos y desbordan, como rebabas — por todos los lados de su superficie_, las meras asociaciones de imágenes. Este carácter asociativo del lenguaje es lo que permite que las imágenes establezcan un vínculo sensible en el proceso de la lectura. Las imágenes asociadas estructuran el conjunto de relaciones con las que se vinculan los sujetos políticos compuestos por el lenguaje y el territorio en el que se asientan y realizan sus acciones.

6. De allí surge el hecho de que, un poco en broma y un poco en serio, se pueda hablar de un realismo elástico que en Elástico de sombra se puede percibir, entre otras cosas, en el documentalismo y los guiños a una ficción documental que supone que ciertos personajes se correspondan, con nombre y apellido, con activistas, militantes y líderes de las comunidades negras e indígenas del Cauca, como Francia Márquez o Feliciano Valencia, entre otros. 
Escribir por detrás: Permanencia y duración en Elástico de sombra, de Juan Cárdenas

Pero al tratarse de sujetos políticos entramados en el lenguaje, son también sujetos que tienen la permanente voluntad de llevar adelante la práctica ancestral de la resistencia y cuyo posicionamiento dinámico se diluye, se disuelve y se entremezcla proyectándose hacia una colectividad que se identifica ya no solo gracias al lenguaje sino también gracias al territorio, ese territorio que, en el caso de Elástico de sombra se corresponde con el norte del Cauca, allí donde las comunidades de La Balsa, Suárez, Buenos Aires, Timba, La Toma, Puerto Tejada, Miranda, Santander de Quilichao, Guachené, Villarrica, el Bordo, Caloto, el río Patía o Caldono, merodean por Popayán — esa «máquina de fachadas blanqueadas donde durante siglos se legalizó, se naturalizó y hasta se embelleció el despojo» (Cárdenas, 2019, p. 87)-.

En este sentido, es una novela que, sobre el territorio, sitúa personajes que ponen en funcionamiento todo un imaginario - un arsenal de imaginación - acerca de las distintas formas de las etnicidades en torno a las que se articulan discursos y activismos. Esa articulación da cuenta de prácticas políticas, de formas de ocupar y proteger el territorio, así como de experiencias sociales que buscan desacoplar esencialmente tres asuntos: las violencias de la modernidad impuesta por la blanquitud, sus históricos despojos y la «calamitosa historia del colonialismo como la principal manifestación política del Iluminismo» (2018, p. 77), como lo diría William Kentridge en una de sus Seis lecciones de dibujo, al mostrar que todo acto de iluminación conlleva una sombra y una violencia que le acompaña.

Dentro de esta lógica narrativa, Cero — personaje burlonamente autorreferencial «que tenía por oficio escribir mamotretos $[\mathrm{y}]$ no dejaba de tomar nota en una libretita roja» y quien «víctima del hechizo de una bruja poderosa» termina convertido en cucarrón y sin su «apabullada y arrecha humanidad» (Cárdenas, 2019, p. 72) — tiene una particularidad y es que sus transformaciones ejemplifican significativamente el desplazamiento desjerarquizador que se produce incluso desde la supuesta centralidad del no poco «atembado» sujeto letrado, escritor afincado a su manera en la tradición etnográfica y quizás costumbrista a quien «algunos estudiosos [...] acusaban de ladrón y apropiadorcista de lo ajeno» (p. 11), pero en cuyas transformaciones puede reconocerse un desplazamiento desde el centro letrado - que es, por supuesto, el centro urbano del que proviene - hacia los territorios de lo popular, ese valle endemoniado al que arrastra consigo todo el arsenal archivístico con el que carga. En todo caso Cero es un personaje que no oculta su pertenencia a lo blanco, lo citadino y lo letrado, lugares desde los que acompaña a los lectores a través de la trama. Esto es algo que aparece enunciado a través de una de las reflexiones de Miguel, cuando señala que quizás

Cero no era la persona indicada para contar cosas de negros, quizás esa labor le correspondía a los propios negros y no a un intelectual cafeconleche... Quién sabe... igual, concluyó Miguel, su amigo no era ningún apropiador de las cosas de los negros, sino más bien una especie de contrabandista, alguien que lleva y trae cosas de un lado a otro, brincándose y en últimas tratando de borrar las fronteras raciales que el hombre blanco inventa para garantizar su derecho de dominación, para marcar el terreno con su sistema de medidas. Y aunque a veces tenía dudas sobre la legitimidad de sus actividades, Cero en últimas se cagaba en todo ese complejo mecanismo de segregación y no permitía que le dijeran desde dónde hablar y cómo (p. 73).

Esta caracterización hiperbólica y caricaturizada de la figura de Cero expone el carácter colonial de la blanquitud al tiempo que habilita su desmontaje, ya que se trata de una figura que pone en cuestión la blanquitud 
Escribir por detrás: Permanencia y duración en Elástico de sombra, de Juan Cárdenas

con que ha sido construida violentamente una idea de lo nacional y hace aparecer otras concepciones de la nación y de la territorialidad. Esto lo hace subrayando la diferencia — esa otredad en la concepción de lo nacional—y la participación de actores sociales que han sido históricamente excluidas, como las comunidades negras del norte del Cauca. Al situar lo regional y lo étnico como un problema de exclusión del Estado, en Elástico de sombra se conciben los saberes populares, entre ellos la esgrima de machete, como materialidades sincrónicas que tienen y llevan a cabo sus propias lógicas transhistóricas, absolutamente inconexas con el plan modernizador hegemónico del Estado nación impuesto por la blanquitud. Esa tensión entre la ciudad letrada y los discursos movilizadores de la resistencia, que la novela resuelve con la figura de Cero y su transformación zoomórfica, dilata los límites de la ciudad letrada y los altera al mostrarles la posibilidad de incorporarse a una relación plena —aunque no necesariamente armónica - con las discursividades de la resistencia ancestral. Esos límites son dilatados por las retransmisiones de las acciones de resistencia y por el ordenamiento del lenguaje como partícipe pleno de esas acciones, sin interrumpirlas, sin invadirlas, sin inmiscuirse en ellas.

\section{La escritura: recordar escondiendo para resistir}

Si bien la novela de Cárdenas sirve para exponer algunos rasgos fundamentales del discurso con el que ha sido representada la resistencia negra en Colombia, y está enmarcada en el contexto de las resistencias del presente, es justo advertir que, en tanto acción de resistencia, se trata de una síntesis creativa entre la novela comprometida, o lo que podría reconocerse como tal, y lo que Walter Benjamin (1971) llama una «novela cifrada», aquella donde se produce, como en Nadja, de André Breton, una «iluminación profana» (p. 47). Solo que en este caso la iluminación se produce en la parte trasera de la hoja, allí donde la modernidad, su racismo, sus violencias y sus desaforadas acumulaciones de capital no ha hecho otra cosa que propagar los restos de sus despojos; allí donde la escritura funciona como un dispositivo de memoria que esconde para resistir.

Planteadas dos de las múltiples gradaciones de la intensidad de la duración que hay en Elástico de sombra puede verificarse que la escritura por detrás es más una escritura en resistencia que una escritura sobre la resistencia. No es una escritura que se asienta en el lugar de la observación —y por ello no se puede decir que Elástico de sombra es un relato etnográfico - sino una escritura que, en la exploración de las variaciones del relato, interviene ${ }^{7}$ desde $^{-}$ la perspectiva de la resistencia. Es una novela performativa en el sentido de que forma parte de la puesta en escena de las prácticas de resistencia y no se sostiene tras un pacto de representación, sino, más bien, de presentación de la historia, algo que Cárdenas hace explícito cuando en la «Nota liminar» posiciona la novela frente a una condición histórica y política específica. En efecto, Cárdenas (2019) vinculó la obra con la resistencia negra al insistir en que con su escritura

esper[a] contribuir a la memoria y al presente de las luchas negras de toda América, además de ofrecer herramientas para el que sin duda es el proyecto más urgente de la cultura universal, a saber, la aniquilación definitiva del Hombre Blanco (p. 7).

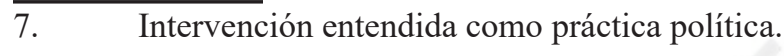


Escribir por detrás: Permanencia y duración en Elástico de sombra, de Juan Cárdenas

En su carácter performativo, Elástico de sombra interviene como práctica discursiva que interpela la blanquitud de las élites, a la vez que hace visible la tragedia en la cultura y en la historia. Pero con ello también hace visible la cultura en la tragedia, parafraseando a Didi-Huberman (2012), para no separarla de su memoria (p. 26). Giorgi (2020) percibió en la narrativa de Cárdenas un retorno al archivo, un volver a aquello que ha sido tachado por ejemplo, lo afrocolombiano del siglo XIX - , un volver a ese «conocimiento mudo que ha sobrevivido a las sucesivas y violentas borraduras de memoria a las que fueron sometidos los negros traídos por la fuerza a vivir en estas tierras» (Cárdenas, 2019, p. 45) y cuya supresión, como reflexiona uno de los maestros macheteros de la novela, «ha dejado marcas en los cuerpos» ( p. 47).

Giorgi (2020) también se refirió a «una exploración sobre el archivo inestable que está puesto en cuestión y en disputa» (s.p.) y afirmó que en novelas como Los estratos, El diablo en las provincias y Elástico de sombra, la narrativa de Juan Cárdenas «vuelve la mirada hacia ese archivo para interpelar la nación extractiva y lo hace a través de un archivo de procedimientos cuya referencia paradigmática es La vorágine, como un texto que pone en escena la frontera de acumulación del capital» (s.p.). En efecto, la resistencia de la que participa la escritura de Cárdenas solo puede existir dentro de un horizonte temporal que es controlado por el capital. Pero lo que hace justamente la escritura en resistencia es convocar la torcedura de ese horizonte arrasador, violento, apropiador, despojador, que es la unidad del tiempo del capital. La escritura en resistencia se mantiene en contra de esa unidad del tiempo, o mejor aún, mantiene su duración en ese (contra)tiempo que es la permanencia alterada. Giorgi agregó finalmente que una narrativa como la de Cárdenas pone en escena matices, tensiones y límites de lo nacional, ya que en ella aparece un archivo de lo nacional que ha sido tachado. Esto implica la existencia de una narrativa que propone formas de imaginar territorialidades que no se corresponden con lo nacional.

Esa puesta en escena que trasciende lo nacional surge de la superposición entre el dinamismo narrativo que caracteriza la escritura de Cárdenas y una explícita toma de posición desde donde esa escritura se enuncia. La escritura de este autor no se limita a relatar formas de la resistencia de manera anecdótica, sino que estas formas en resistencia, y aún más, las temporalidades con que esas formas en resistencia se producen, son incorporadas también en el uso y en el ordenamiento del lenguaje. De ahí que, en sentido barthesiano, sea posible reconocer un estilo «Cárdenas», es decir, una serie de rasgos característicos de su escritura que pueden extraerse de un código mayor — el lenguaje — y que se plantean como distancia y diferencia, pero no son más que una transformación, un procedimiento de la cita, un depósito de cultura (Barthes, 2003, p. 157). El ordenamiento que Elástico de sombra le da al lenguaje y con el cual se estructura la novela es el resultado de la tensión generada por la presentación —no representación — de un pathos, el de la resistencia negra, y la conservación y proliferación de un relato, el de las múltiples tradiciones que conviven en su existencia como texto.

Estas capas superpuestas de presentación, conservación y proliferación resuelven la estructura de la novela al constituirse como un sistema de relaciones entre la permanencia y la duración, que conllevan una serie de procedimientos en función de la inscripción, la identificación y el trazado de la diferencia. Al usar fragmentos culturales transhistóricos, como los mitos, las leyendas, las prácticas olvidadas, los saberes ancestrales, los saberes 
populares, y los saberes letrados, entre otros, la permanencia y la duración, en tanto agentes que articulan el relato, se entrelazan a través del ordenamiento del lenguaje. Así, sostienen entre ellas un sistema de relaciones de intensidades que hacen de la novela de Cárdenas una narración intensa, no solamente en lo que refiere a su ritmo y su velocidad — que está, por demás, cargado de intensidades - sino porque es una narración que insiste, una narración que pone el pie firmemente sobre un compromiso social, una narración que toma una posición. 


\section{Referencias bibliográficas}

1. Antelo, R. (2019). La elipse americana. Volver de la nada y volverse a ir a la nada. Letral, 21, 113-134.

2. Ararat, L.; Mina, E.; Rojas, A.; Solarte, A.M.; Vanegas, G.; Vargas, L. A. \& Vega, A. (2013). La Toma: historias de territorio, resistencia y autonomía en la Cuenca del Alto Cauca. Popayán: Observatorio de Territorios Étnicos (Pontificia Universidad Javeriana), Consejo Comunitario Afrodescendiente de La Toma.

3. Arocha Rodríguez, J. (1995). Unidades de producción nortecaucanas (Colombia): modernización y funcionamiento. América Negra, 9, 185-205.

4. Arocha Rodríguez, J. (2016). Nina S. de Friedemann (1930-1998): La etnógrafa de africanías y cimarronismos. Revista de Estudios Colombianos, 47, 136-150.

5. Barbary, O. y Urrea, F. (2003). Introducción. En O. Barbary y F. Urrea (Eds.), Gente negra en Colombia. Dinámicas sociopolíticas en Cali y el Pacífico (pp. 21-65). Medellín: Centro de Investigaciones y Documentación Socioeconómica (CIDSE, Universidad del Valle), L'Institut de Recherche pour le Développement (IRD), Colciencias.

6. Barthes, R. (2003). El estilo y la imagen. En R. Barthes, El susurro del lenguaje (pp. 147-157). Madrid: Editora Nacional.

7. Benjamin, W. (1971). El surrealismo. La última instantánea de la inteligencia europea. En W. Benjamin, Imaginación y sociedad. Iluminaciones I (pp. 43-62). Madrid: Taurus.

8. Beverly, J. (2004). Subalternidad y representación. Debates en teoría cultural. Madrid: IberoamericanaVervuert.

9. Bolívar, M. C. \& Ibarra, M. E. (2017). Las mineras de La Toma. Resistencia negra en defensa de la vida y el territorio. Pensamiento Americano, 10, 155-174.

10. Braudel, F. (1969). La larga duración. En F. Braudel, La historia y las ciencias sociales (pp. 60-106). Madrid: Alianza.

11. Cárdenas, J. (2019). Elástico de sombra. México: Sexto Piso.

12. Cárdenas, J. (2020). La gran conspiración contra el Mediterráneo. El País, Opinión. https://elpais. com/opinion/2020-06-22/la-gran-conspiracion-contra-el-mediterraneo.html?fbclid=IwAR3O4Je8 CetNhDs7dKLf7ocLdrD00TEXsOsjtv9Nx1GB7Yah6nW4OqYheY\%20

13. Colombi, B. (2006). La gesta del letrado (sobre Ángel Rama y La ciudad letrada). Orbis Tertius, 11-12, 1-6. http://sedici.unlp.edu.ar/handle/10915/10580 (23/04/2020).

14. Deleuze, G. (2008). ¿Qué es el acto de la creación? En G. Deleuze, Dos regímenes de locos. Textos y entrevistas (1975-1995) (pp. 281-289). Valencia: Pre-textos.

15. Del Llano, A. (1995). Voces y huellas de la oralidad: un encuentro con Martín Lienhard. CELEHIS: Revista del Centro de Letras Hispanoamericanas, 4-5, 293-302.

16. Didi-Huberman, G. (2012). Arde la imagen. Oaxaca: Serieve. 
Escribir por detrás: Permanencia y duración en Elástico de sombra, de Juan Cárdenas

17. Echeverría, B. (2011). Imágenes de la blanquitud. En B. Echeverría, Crítica de la modernidad capitalista. Antología Bolivar Echeverría (pp. 145-160). La Paz: Vicepresidencia del Estado Plurinacional de Bolivia.

18. Fisher, M. (2018). "Siempre has sido el conserje": Los espacios espectrales del Hotel Overlook. En M. Fisher, k-punk. Volumen I (pp. 247-259). Buenos Aires: Caja Negra.

19. García-Hípola, M. (2011). Permanencia alterada. Las ciudades de excavación artificial de Peter Eisenman. Proyecto, Progreso, Architectura, 4, 16-29.

20. Giorgi, G. (2020). Entrevista a Gabriel Giorgi. Conversaciones con el SILAT. https://open.spotify.com/ episode/71LdJHwM3L4C1tBKyFIyTV

21. Henao, S. y Delgado, A. L. (2020). El banano, signo de la duración. Mimeo.

22. Hernández, E. (2006). La resistencia civil de los indígenas del Cauca. Papeles políticos, 11(1), 177-220.

23. Jaramillo, E. y Rojas, A. (Eds.) (2019). Pensar el suroccidente. Antropología hecha en Colombia. Cali: Asociación Latinoamericana de Antropología, Universidad ICESI.

24. Kentridge, W. (2018). Breve historia de las revueltas coloniales. Seis lecciones de dibujo (pp. 59-104). Buenos Aires: El Hilo de Ariadna.

25. Lasso, M. (2013). Mitos de armonía racial: raza y republicanismo durante la era de la revolución, Colombia 1795-1831. Bogotá: Universidad de los Andes.

26. Lienhard, M. (2003). La voz y su huella. México: Universidad de Ciencias y Artes de Chiapas.

27. Mazzoldi, B. (2020). Sobrevida(s): Homenaje a Jacques Derrida en su 90 aniversario. Instantes y azares, 29'. https://www.youtube.com/watch?v=WN1AJ9t78sI

28. Mina, M. (1975). Esclavitud y libertad en el valle del río Cauca. Bogotá: Publicaciones de la Rosca.

29. Molano, A. (2017). De río en río. Vistazo a los territorios negros. Bogotá: Aguilar.

30. Múnera, A. (1998). El fracaso de la nación: Región, clase y raza en el Caribe colombiano (1717-1821). Bogotá: El Áncora Editores, Banco de la República.

31. Rama, Á. (1982). La señal de Jonás sobre el pueblo mexicano. Escritura, 10, 179- 239.

32. Rappaport, J. (2000). La política de la memoria: interpretación indígena de la historia en los Andes colombianos. Popayán: Universidad del Cauca.

33. Restrepo, E. (2003). Esencialismo étnico y movilización política: tensiones en las relaciones entre saber y poder. En O. Barbary y F. Urrea (Eds.), Gente negra en Colombia. Dinámicas sociopolíticas en Cali y el Pacífico (pp. 227-244). Medellín: Centro de Investigaciones y Documentación Socioeconómica (CIDSE, Universidad del Valle), L'Institut de Recherche pour le Développement (IRD), Colciencias.

34. Taussig, M. (1979). Destrucción y resistencia campesina: el caso del litoral pacífico. Bogotá: Punta de Lanza. 35. Taussig, M. (1993). El diablo y el fetichismo de la mercancía en Sudamérica. México: Nueva Visión.

36. Zgaib, I. (2020). Es un nuevo mundo, amor. La Vida Útil, 3, 30-41.

37. Zuluaga, F. (2010). La resistencia afrodescendiente en la Gobernación de Popayán. Anuario de Historia Regional y de las Fronteras, 15, 91-112. 
Escribir por detrás: Permanencia y duración en Elástico de sombra, de Juan Cárdenas

38. Zuluaga, P. A. (2018). Tenemos un gran desafío: transformar las políticas de muerte en políticas para la vida. Contexto y Acción, 185. https://ctxt.es/es/20180905/Politica/21487/Pedro-Adrian-Zuluaga-Francia-Elena-Marquez-activismo-Colombia-transformacion-politico.htm

39. Zemelman, H. (2011). Los horizontes de la razón. III. El orden del movimiento. Barcelona-Manizales: Anthropos-CECCAL. 